\title{
Ultrasound Biomicroscopy Measurements of the Normal Thickness for the Ciliary Body and the Iris in a Middle East Population
}

\author{
Yacoub A Yousef' \\ Mona Mohammad' \\ Ibrahim AINawaiseh' \\ Reem AlJabari' \\ Mario Damiano Toro $\mathbb{D}^{2,3}$ \\ Almutez Gharaibeh ${ }^{4}$ \\ Robert Rejdak ${ }^{5}$ \\ Katarzyna Nowomiejska ${ }^{5}$ \\ Sandrine Zweifel ${ }^{3}$ \\ Teresio Avitabile ${ }^{6}$ \\ Magdalena Rejdak ${ }^{6}$ \\ Rashed Nazzal (iD ${ }^{2}$ \\ 'Department of Surgery (Ophthalmology), \\ King Hussein Cancer Centre, Amman, \\ Jordan; ${ }^{2}$ Faculty of Medical Sciences, \\ Collegium Medicum, Cardinal Stefan \\ Wyszyński University, Warsaw, Poland; \\ ${ }^{3}$ Department of Ophthalmology, University \\ of Zürich, Zürich, Switzerland; ${ }^{4}$ School of \\ Medicine, The University of Jordan, \\ Amman, Jordan; ${ }^{5}$ Department of General \\ Ophthalmology, Medical University of \\ Lublin, Lublin, Poland; ${ }^{6}$ Department of \\ Ophthalmology, University of Catania, \\ Catania, Italy
}

Purpose: Ciliary body (CB) and iris thicknesses may change with certain eye diseases as well as between different populations. Here, we report Ultrasound Biomicroscopy Measurements (UBM) of the normal thickness for the CB and the iris from a homogenous population in the Middle East.

Patients and Methods: Sonomed 35-MHz (SONOMED, INC. New York, USA) images were obtained at 4 radial meridians, and the thickness was measured at 3 locations along the radial length of the iris and at the thickest part of the $\mathrm{CB}$. Parameters included mean thickness, median thickness, range, and standard deviation.

Results: Of 46 adult patients, 83 normal eyes were included in this analysis. The overall mean, median iris thicknesses at the iris root, midway along the radial length of the iris, and at the juxtapupillary margin in mm were $0.42,0.41 \pm 0.08,0.52,0.51 \pm 0.08$, and $0.72,0.71 \pm 0.1$, respectively. The overall mean, median thicknesses of the $\mathrm{CB}$ and $\mathrm{CB}+$ ciliary processes in $\mathrm{mm}$ were $0.72,0.71 \pm 0.1$, and $1.42,1.37 \pm 0.2$ respectively. Gender, age, side, and height had no impact on iris and/or CB thickness ( $>0.05$ ). However, the iris thickness was significantly thicker in the superior quadrant than inferiorly, and in the nasal quadrant than the temporal quadrant $(\mathrm{p}=0.04)$, and the $\mathrm{CB}$ thickness and the $\mathrm{CB}+$ ciliary processes thickness were significantly thicker in the superior quadrant than inferiorly ( $\mathrm{P}=0.04$ and 0.02 consecutively).

Conclusion: We measured in this study the normal thickness of the $\mathrm{CB}$ and the iris in normal eyes from homogenous population in the Middle East using ultrasound biomicroscopy. Our findings are essential for the ophthalmic community worldwide and in the Middle East region and can be used as a normative thickness data for the iris and CB in healthy eyes.

Keywords: ultrasound biomicroscopy, iris, ciliary body

\section{Introduction}

Different eye diseases can cause morphological changes in the structures of the anterior segment including the ciliary body (CB) and the iris. ${ }^{1-3}$ These morphologic changes can be detected by ultrasound biomicroscopy (UBM) and anterior segment optical coherence tomography (OCT), and they include thickening or displacement related to different intraocular tumors (eg, CB melanoma, anterior chamber metastasis, iris melanoma, leiomyoma, and medullo-epithelioma), ${ }^{1-6}$ and thickening of both the $\mathrm{CB}$ and the iris by infiltrative processes (eg, lymphoma, metastasis, uveitic granulomas, retinoblastoma, and intraocular invasion by conjunctival tumor). ${ }^{7-10}$ Similarly, glaucoma and intraocular implants have been shown to be associated with variable changes in the morphology of the anterior segment. ${ }^{11-17}$ 
UBM was first developed by Pavlin's group in Canada in the $1990 \mathrm{~s},{ }^{1}$ and this technique is primarily used for imaging of the anterior segment of the eye by obtaining cross-sections of the eye at microscopic resolution. ${ }^{1}$ Rather than the regular ultrasound modalities such as B-scan or A-scan (8-12 MHz), UBM uses a much higher frequency transducer $(35-100 \mathrm{MHz}){ }^{3-8}$ This results in resolutions up to $20 \mathrm{um}$ axially and 50um laterally, and the depth of tissue penetration is $4-5 \mathrm{~mm}$. Therefore, UBM is used for imaging of the anterior anatomy of the eye, including iris diseases, iridotomy, iridectomy, CB cysts, angle closure glaucoma, CB melanoma, angle trauma, as well as conjunctival pathologies. ${ }^{3-12}$

Ultrasound biomicroscopy is an important tool for assessment of the anatomy of the anterior chamber including cataract, glaucoma, and congenital anomalies of the anterior segment. These images may affect surgical planning based on the status of each eye. ${ }^{25,26}$ Knowledge about normative data about biometrics of the anterior part of the eye including the thickness of the $\mathrm{CB}$ and the iris are needed as normative comparative data to evaluate the pathology based on normal reference measurements. ${ }^{25}$ Unfortunately, very few UBM and anterior segment OCT studies looked at the normal eyes and came with measurable normative data. ${ }^{13-15}$ Even though, they demonstrated how knowledge of normative values can serve as a basis for determinations of abnormal thickness, and how eyes with thicker than the normal range need to be monitored for abnormal changes or even for tumor growth. This UBM study reports the normal thickness measurements of the $\mathrm{CB}$ and the iris in normal eyes from a homogenous population in the Middle East, and our results will be a valuable addition for the limited normative iris and $\mathrm{CB}$ thickness data in the literature.

\section{Patients and Methods}

This is a retrospective study of 83 normal eyes from 46 patients treated in the eye clinic at King Hussein Cancer Center (KHCC) from 2015 to 2019. All eyes that were included in this study had completely normal ophthalmic examination. Study inclusion required access to patient's medical records and UBM images. The data collected included patient's age, gender, laterality, iris color, weight and height. This study was approved by the KHCC Institutional Review Board (20KHCC127) and it was conducted in accordance with the Declaration of Helsinki.

$35-\mathrm{MHz}$ UBM images were obtained as routine standardized exam at 4 locations (12-, 3-, 6-, and 9-o'clock radial meridians). The thickness was measured at 3 different locations along the radial length of the iris (at the iris root, midway along the radial length of the iris, and at the juxtapupillary margin) and at the thickest part of the CB. Parameters included mean thickness, median thickness, range, and standard deviation.

\section{Inclusion and Exclusion Criteria}

As part of our routine practice at KHCC, UBM is done for many cancer patients to rule out the possibility of intraocular malignancy as metastasis to the ciliary body or the angle, lymphoma involving the uveal tissue, and for comparison with the thickness of the iris and ciliary body in the other eye if it harbored tumor like ciliary body ring melanoma. In this study inclusion criteria included all normal eyes with mild or no refractive error (spherical equivalent between -2.0 and +2.0 ) that were examined by UBM by the same person (YAY) as a routine standardized exam at 4 locations (12-, 3-, 6-, and 9-o'clock radial meridians) and had their scans documented and saved in the machine. Exclusion criteria included eyes that had history of ocular disease, glaucoma, trauma, ocular laser treatment, intraocular surgery, those who received radiation therapy for the eye or the head and neck region. Eyes with high refractive errors (spherical equivalent more than +2.0 or less than -2.0) were excluded from this study.

\section{Examination Technique}

The UBM examination technique was done in the outpatient eye clinic. Transducer direction and manipulation of the probe is guided by looking at the image on the screen. The patient was examined in a supine position facing the ceiling. After topical anesthesia ( $0.4 \%$ Oxybuprocaine hydrochloride; Bausch \& Lomb UK Limited), a specially-designed rubberized immersion eye cup (small, medium, and large size 20, 22, and $24 \mathrm{~mm}$ diameter) was used to separate the eyelids and form a water bath environment. This cup was filled with normal saline, and was held against the globe with just enough pressure to prevent leakage of fluid. Each participant was imaged with UBM using the Sonomed 35-MHz high-frequency ultrasound system (SONOMED, INC. New York, USA). Radial (longitudinal) views of the angle at the 12-, 3-, 6-, and 9-o'clock positions were obtained from both eyes and were saved as a marked video. In retrospect, the saved images were reviewed, and the system's integrated measurement calipers were used to obtain the following measurements at each of the four radial views for every single eye included in this study (Figure 1): 

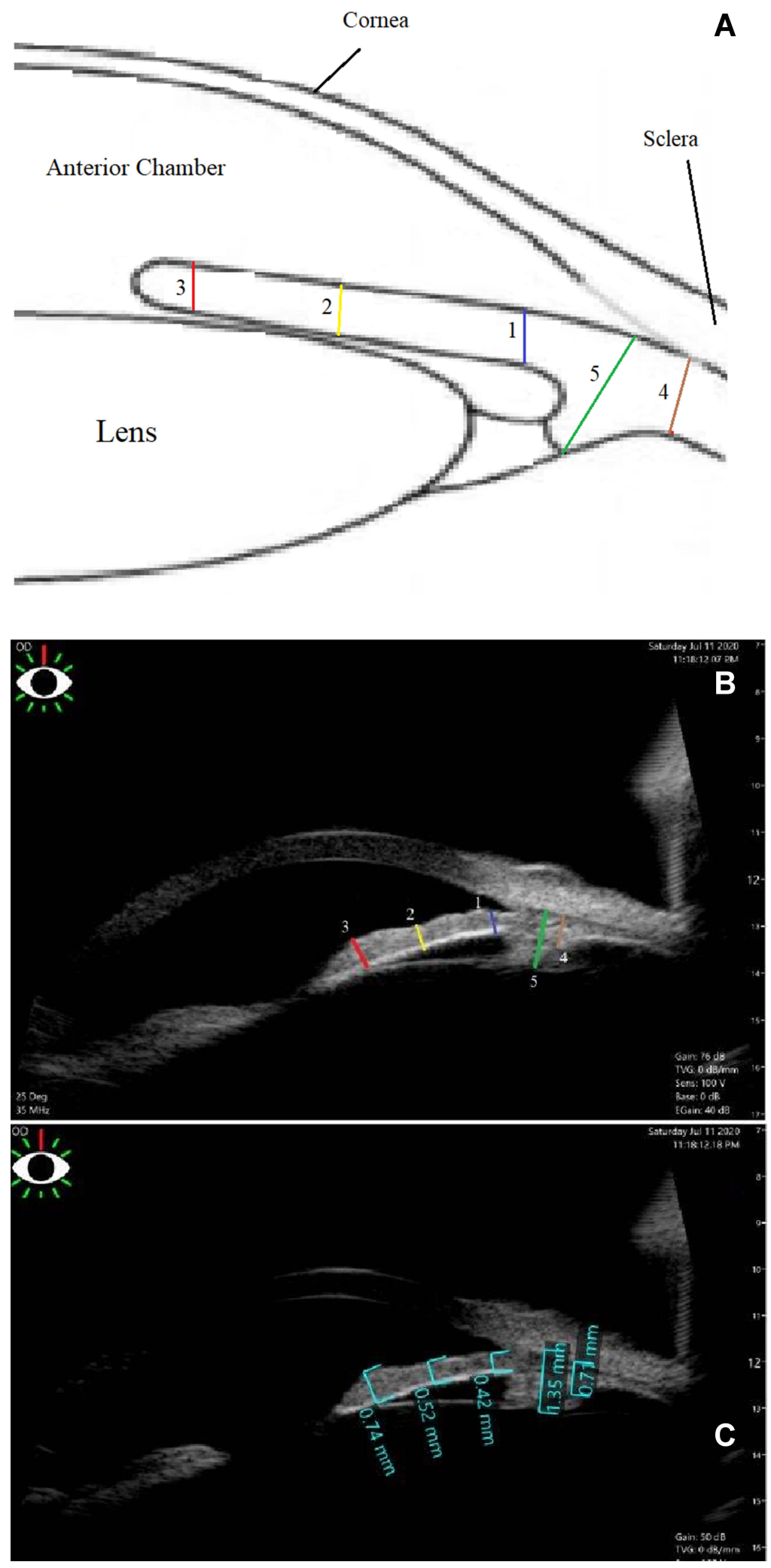

Figure I Ultrasound biomicroscopy (UBM). (A) shows a scheme and (B) shows a real Image of the iris and the ciliary body depicting where thickness measurements of the iris [iris thicknesses at $0.8 \mathrm{~mm}$ from the iris root (I, blue line), midway along the radial length of the iris (2, yellow line), and at the juxtapupillary margin ( 3 , red line)], and the ciliary body [ciliary body (4, blue line), and ciliary body with ciliary processes (5, green line)] were obtained. (C) Real measurements for one of the patients were the iris thicknesses at $0.8 \mathrm{~mm}$ from the iris root was $0.42 \mathrm{~mm}$, at midway along the radial length of the iris was $0.52 \mathrm{~mm}$, and at the juxtapupillary margin was $0.7 \mathrm{~mm}$. The ciliary body thickness was $0.72 \mathrm{~mm}$ and the ciliary body with ciliary processes thickness was $1.38 \mathrm{~mm}$. 
1. Iris thickness at $0.8 \mathrm{~mm}$ from the iris root.

2. Iris thickness at midway along the radial length of the iris from its root to the pupillary margin.

3. Iris thickness at the juxtapupillary margin (thickest part of the iris within $1 \mathrm{~mm}$ from the pupil).

4. Maximum $\mathrm{CB}$ thickness was measured as the distance from the inner point of the ciliary body (apex of the ciliary body) to the inner wall of the sclera (perpendicular to the scleral wall).

5. Maximum $\mathrm{CB}+$ ciliary process thickness was measured as the distance from the most inner point of the ciliary process to the inner wall of the sclera (perpendicular to the scleral wall).

All images and measurements were obtained by the same person (Y.A.Y.), and were performed uniformly in a room with sunlight and with the iris in a normal physiologic state. Dilating drops were avoided because they are known to both shorten the radial length of the iris and alter its thickness during mydriasis. The measurements were taken at 2 different times, and the average between the 2 measurements was considered in this study.

\section{Statistical Analysis}

Analyzed parameters included mean thickness, median thickness, range, and standard deviation. The significance and statistical difference of means between each two groups was tested by $t$ test, and values of 0.05 or less were considered significant.

\section{Results}

Eighty-three consecutive healthy eyes of 46 patients were included in this study. All were adult patients from the Middle East with no ethnic differences, and all had brown iris color. Eighteen (39\%) were women and 28 (61\%) were men. The average age of our subjects was 38 years (median: 37 years, range: 22 to 65 years).

\section{Ciliary Body Measurements}

Overall, the mean and median thickness of the CB were $0.72,0.71 \pm 0.1 \mathrm{~mm}$ (range: 0.43 to $1.14 \mathrm{~mm}$ ), and of the $\mathrm{CB}+$ ciliary processes were $1.42,1.37 \pm 0.2 \mathrm{~mm}$ (range: 1.2 to $1.75 \mathrm{~mm}$ ) (Table 1 ).

There was no significant difference in the mean $\mathrm{CB}$ thickness $(\mathrm{P}=0.33)$ or $\mathrm{CB}+$ ciliary processes thickness $(\mathrm{P}=0.43)$ between males and females, and in the mean $\mathrm{CB}$ thickness $(\mathrm{P}=0.70)$ or $\mathrm{CB}+$ ciliary processes thickness $(\mathrm{P}=0.49)$ between right and left eyes after adjusting the effect of eye sites. On the other hand, there was a trend for patients less than 40 year and taller than $160 \mathrm{~cm}$ to have thicker CB and ciliary process, however these differences were not statistically significant (Table 1 ).

In terms of eye quadrant, there was no statistically significant difference in $\mathrm{CB}$ thickness and in $\mathrm{CB}+$ ciliary processes thickness $(\mathrm{P}=0.89)$ between nasal and temporal quadrants $(\mathrm{P}=0.28)$. However, the $\mathrm{CB}$ thickness and the $\mathrm{CB}+$ ciliary processes thickness were significantly thicker in the superior quadrant than inferiorly ( $\mathrm{P}=0.04$ and 0.02 consecutively).

\section{Iris Measurements}

Overall, the mean and median thickness of the iris at $0.8 \mathrm{~mm}$ from the iris root were $0.42,0.41 \pm 0.08 \mathrm{~mm}$ (range: 0.29 to $0.65 \mathrm{~mm}$ ), at midway along the radial length of the iris were $0.52,0.51 \pm 0.08 \mathrm{~mm}$ (range: 0.31 to $0.73 \mathrm{~mm}$ ), and at the iris at its thickest part close to the juxtapupillary margin were $0.72,0.71 \pm 0.1 \mathrm{~mm}$ (range: 0.42 to $0.93 \mathrm{~mm}$ ) (Table 2).

There was no statistically significant difference in iris thicknesses by gender, age, patient's height, or eye side (Table 2). In terms of eye quadrant, the iris thickness at the three measured locations were significantly thicker in the superior quadrant than inferiorly $(\mathrm{P}=0.04$ and 0.02 consecutively), and in the nasal quadrant than the temporal quadrant ( $\mathrm{p}$ values in Table 2).

\section{Discussion}

Normative data about the normal thickness of the CB and the iris is important as a comparative data to evaluate ocular pathology based on normal reference measurements, since the structure of both the $\mathrm{CB}$ and the iris changes in morphology and/or thickness with different ocular diseases including benign and malignant tumors. UBM can aid in defining normal vs abnormal CB and iris quantitatively, and our results here will help as an additive reference for normal values to quantify and/or determine ocular changes.

Ultrasound biomicroscopy is an important tool for assessment of the anatomy of the anterior chamber including cataract, glaucoma, and congenital anomalies of the anterior segment. These images may affect surgical planning based on the status of each eye. Knowledge about normative data about biometrics of the anterior part of the eye are needed to discriminate normal UBM findings from abnormal findings. ${ }^{25}$ Even more, it shown to be helpful diagnostic tool to evaluate causes of pseudophakic glaucoma through adequate visualization of different angle 
Table I Ciliary Body Thickness (mm) Comparison by Gender, Age, Height, Eye and Quadrant [Mean, Median \pm SD (Range)]

\begin{tabular}{|c|c|c|}
\hline Parameter & Ciliary Body & Ciliary Body + Ciliary Processes \\
\hline Over all thickness ( 83 eyes) & $0.72,0.71 \pm 0.1(0.43-1.14)$ & $1.42,1.37 \pm 0.2(1.20-1.75)$ \\
\hline \multicolumn{3}{|c|}{ Gender } \\
\hline Female $(\mathrm{n}=3$ leyes, 18 patient $)$ & $0.70,0.69 \pm 0.10(0.43-1.14)$ & $1.40,1.35 \pm 0.10(1.20-1.70)$ \\
\hline Male ( $n=52$ eyes, 28 patient) & $0.72,0.70 \pm 0.10(0.45-1.12)$ & $1.44,1.38 \pm 0.10(1.32-1.75)$ \\
\hline$P$ value & 0.33 & 0.43 \\
\hline \multicolumn{3}{|c|}{ Age (year) } \\
\hline$<40(n=48)$ & $0.75,0.74 \pm 0.2(0.47-1.14)$ & $1.44,1.40 \pm 0.2(1.25-1.75)$ \\
\hline$>40(n=35)$ & $0.70,0.69 \pm 0.1(0.43-1.08)$ & $1.38,1.36 \pm 0.1(1.20-1.60)$ \\
\hline$P$ value & 0.54 & 0.66 \\
\hline \multicolumn{3}{|c|}{ Height } \\
\hline$<160 \mathrm{~cm}(\mathrm{n}=49)$ & $0.7 I, 0.70 \pm 0.1(0.43-I . I)$ & $1.40,1.34 \pm 0.1(1.20-1.60)$ \\
\hline$>160 \mathrm{~cm}(\mathrm{n}=34)$ & $0.74,0.72 \pm 0.2(0.46-1.14)$ & $1.45,1.38 \pm 0.2(1.30-1.75)$ \\
\hline$P$ value & 0.93 & 0.78 \\
\hline \multicolumn{3}{|c|}{ Eye } \\
\hline Right $(n=40)$ & $0.72,0.71 \pm 0.10(0.44-1.12)$ & $1.43,1.38 \pm 0.2(1.3-1.75)$ \\
\hline Left $(n=43)$ & $0.72,0.70 \pm 0.10(0.43-1.14)$ & $1.4 \mathrm{I}, 1.36 \pm 0.2(1.2-1.68)$ \\
\hline$P$ value & 0.70 & 0.49 \\
\hline \multicolumn{3}{|c|}{ Quadrant } \\
\hline Superior $(n=83)$ & $0.74,0.72 \pm 0.10(0.46-1.12)$ & $1.45,1.37 \pm 0.2(1.34-1.75)$ \\
\hline Inferior $(n=83)$ & $0.70,0.69 \pm 0.10(0.43-1.10)$ & $1.40,1.35 \pm 0.2(1.20-1.67)$ \\
\hline$P$ value & 0.04 & 0.02 \\
\hline Nasal $(n=83)$ & $0.73,0.72 \pm 0.10(0.46-1.12)$ & $1.44,1.38 \pm 0.2(1.34-1.75)$ \\
\hline Temporal $(\mathrm{n}=83)$ & $0.70,0.39 \pm 0.10(0.43-1.10)$ & I.40, I. $35 \pm 0.2(1.20-1.67)$ \\
\hline$P$ value & 0.28 & 0.89 \\
\hline
\end{tabular}

Abbreviation: SD, standard deviation.

structures. $^{27}$ For example, secondary angle closure caused by anterior synechiae formation is one of the important causes of post penetrating keratoplasty glaucoma in eyes with opaque grafts, and this is best to be evaluated clinically before the surgery by UBM to avoid such complications, and to help predicting the outcome of this procedure. $^{28}$ Therefore, UBM serves as a useful tool for anterior-segment evaluation in such cases and can help in planning the site for glaucoma filtering surgeries and drainage devices. This is why normative UBM data are needed.
A single UBM study from New York found that the mean thicknesses at the iris root, midway along the radial length of the iris, and at the juxtapupillary margin were reported to be $0.4 \pm 0.1,0.5 \pm 0.1$, and $0.6 \pm 0.1 \mathrm{~mm}$, respectively, and those of the $\mathrm{CB}$ and $\mathrm{CB}+$ ciliary processes were $0.7 \pm 0.1$ and $1.3 \pm 0.2 \mathrm{~mm}$, respectively. ${ }^{13} \mathrm{In}$ our study, we found that the mean thicknesses at the iris root, midway along the radial length of the iris, and at the juxtapupillary margin were $0.42 \pm 0.08,0.51 \pm 0.08$, and $0.72 \pm 0.1 \mathrm{~mm}$, respectively, and those of the $\mathrm{CB}$ and $\mathrm{CB}+$ ciliary processes were $0.72 \pm 0.1,0.6 \pm 0.1$, and $1.42 \pm$ 
Table 2 Iris Thickness (mm) Comparison by Gender, Age, Height, Eye and Quadrant [Mean, Median \pm SD (Range)]

\begin{tabular}{|c|c|c|c|}
\hline Parameter & $0.8 \mathrm{~mm}$ From Iris Root & Mid Iris & Iris Tip \\
\hline Over all iris thickness ( 83 eyes) & $0.42,0.41 \pm 0.08(0.29-0.65)$ & $0.52,0.5 \mathrm{I} \pm 0.08(0.3 \mathrm{I}-0.73)$ & $0.72,0.7 I \pm 0.1(0.42-0.93)$ \\
\hline \multicolumn{4}{|c|}{ Gender } \\
\hline Female $(n=52)$ & $0.4 \mathrm{I}, 0.4 \mathrm{I} \pm 0.08(0.29-0.62)$ & $0.5 \mathrm{I}, 0.5 \mathrm{I} \pm 0.08(0.3 \mathrm{I}-0.70)$ & $0.71,0.70 \pm 0.1(0.42-0.88)$ \\
\hline Male $(n=28)$ & $0.42,0.41 \pm 0.08(0.30-0.65)$ & $0.52,0.51 \pm 0.08(0.32-0.73)$ & $0.73,0.72 \pm 0.1(0.44-0.93)$ \\
\hline$P$ value & 0.93 & 0.93 & 0.89 \\
\hline \multicolumn{4}{|c|}{ Age (Year) } \\
\hline$<40(\mathrm{n}=48)$ & $0.42,0.4 \mathrm{I} \pm 0.08(0.30-0.65)$ & $0.52,0.51 \pm 0.08(0.33-0.73)$ & $0.72,0.71 \pm 0.1(0.43-0.93)$ \\
\hline$>40(n=35)$ & $0.42,0.41 \pm 0.08(0.29-0.62)$ & $0.5 \mathrm{I}, 0.5 \mathrm{I} \pm 0.08(0.3 \mathrm{I}-0.70)$ & $0.7 I, 0.7 I \pm 0.1(0.42-0.90)$ \\
\hline$P$ value & 1.00 & 0.93 & 0.94 \\
\hline \multicolumn{4}{|c|}{ Height } \\
\hline$<160 \mathrm{~cm}(\mathrm{n}=49)$ & $0.40,0.40 \pm 0.08(0.29-0.6 \mathrm{I})$ & $0.5 \mathrm{I}, 0.50 \pm 0.08(0.3 \mathrm{I}-0.70)$ & $0.7 I, 0.70 \pm 0.1(0.42-0.9 I)$ \\
\hline$>160 \mathrm{~cm}(\mathrm{n}=34)$ & $0.42,0.4 \mathrm{I} \pm 0.08(0.3-0.65)$ & $0.52,0.5 \mathrm{I} \pm 0.08(0.34-0.73)$ & $0.73,0.71 \pm 0.1(0.44-0.93)$ \\
\hline$P$ value & 0.73 & 0.73 & 0.84 \\
\hline \multicolumn{4}{|c|}{ Eye } \\
\hline Right $(n=40)$ & $0.42,0.4 I \pm 0.08(0.34-0.65)$ & $0.52,0.51 \pm 0.08(0.32-0.73)$ & $0.72,0.71 \pm 0.1(0.43-0.93)$ \\
\hline Left $(n=43)$ & $0.4 \mathrm{I}, 0.4 \mathrm{I} \pm 0.08(0.29-0.64)$ & $0.5 \mathrm{I}, 0.5 \mathrm{I} \pm 0.08(0.3 \mathrm{I}-0.72)$ & $0.7 I, 0.70 \pm 0.1(0.42-0.9 I)$ \\
\hline$P$ value & 0.93 & 0.94 & 0.89 \\
\hline \multicolumn{4}{|c|}{ Quadrant } \\
\hline Superior $(n=83)$ & $0.44,0.42 \pm 0.08(0.31-0.63)$ & $0.54,0.52 \pm 0.08(0.31-0.70)$ & $0.75,0.73 \pm 0.1(0.45-0.91)$ \\
\hline Inferior $(n=83)$ & $0.38,0.37 \pm 0.08(0.29-0.62)$ & $0.48,0.47 \pm 0.08(0.32-0.7 \mathrm{I})$ & $0.68,0.67 \pm 0.1(0.42-0.89)$ \\
\hline$P$ value & 0.046 & 0.044 & 0.017 \\
\hline Nasal $(n=83)$ & $0.44,0.42 \pm 0.08(0.3 \mathrm{I}-0.65)$ & $0.54,0.52 \pm 0.08(0.33-0.73)$ & $0.74,0.72 \pm 0.1(0.48-0.93)$ \\
\hline Temporal $(n=83)$ & $0.4 \mathrm{I}, 0.40 \pm 0.08(0.3-0.62)$ & $0.49,0.48 \pm 0.08(0.31-0.70)$ & $0.70,0.69 \pm 0.1(0.42-0.90)$ \\
\hline$P$ value & 0.048 & 0.041 & 0.015 \\
\hline
\end{tabular}

Abbreviation: SD, standard deviation.

$0.2 \mathrm{~mm}$, respectively. Our values are very close to the values from New York, ${ }^{13}$ even though our patients had slightly thicker iris and CB. In Japan, the normal CB thickness in 18 adult Japanese control eyes was $0.602 \pm$ $0.08 \mathrm{~mm}$ (mean $\pm \mathrm{SD}$ ) as measurement at $2 \mathrm{~mm}$ posterior to the scleral spur with the aid of UBM. ${ }^{14} \mathrm{CB}$ thickness in Japan $(0.602 \mathrm{~mm})$ was slightly less thick than in our study in the Middle East $(0.72 \mathrm{~mm})$ and in New York $(0.70 \mathrm{~mm}){ }^{13}$

Our study found that iris thickness ranged from 0.29 to $0.93 \mathrm{~mm}$ and $\mathrm{CB}+$ ciliary process thickness ranged from 1.20 to $1.75 \mathrm{~mm}$. This large variation could result from several factors; including brown iris color, pupil diameter, and physiological dilation and constriction of the pupil due to accommodation. ${ }^{18-24}$ Pharmacological dilatation is another factor that may affect the measured thickness, however, we avoided pharmacological dilation for our patients in this study. We also suggested other factors as the age of the patient, patient's height, and different ethical groups as well as ocular pathology or history of ocular surgery. Our study excluded eyes with all forms of ophthalmic pathology and those who had 
any ocular surgery done before. Dilated eyes during the exam are expected to make the iris crowded and to increase its measured thickness. We avoided dilating drops before the exam for all patients; but it is difficult to avoid physiological dilatation due to obstructing the light by the examiner during the examination. Similarly, Garcia et $\mathrm{al}^{13}$ reported a wide range of iris thickness (ranged from 0.2 to $0.9 \mathrm{~mm}$ ) even they avoided therapeutic dilating eye drops. Therefore, variation in iris thickness cannot be explained merely by difference is pupil sized. Unfortunately, pupil size could not be determined accurately in our study because its size is changing during the exam depending on patient's accommodation and on examiner's hands moving over the eye that blocks ambient brightness. All our patients had brown eyes, and have more melanin than colored eyes. This could not be the cause for iris thickness variation and cannot explain why our population has slightly thicker iris and $\mathrm{CB}$ than the report from New York as they showed that all the patients except 2 had brown eyes as well. The ethnic group cannot be considered as underlying cause for variation in iris thickness and $\mathrm{CB}$ thickness since all our patients are from a homogenous population in the Middle East with no ethnical differences. Of interest, Japanese patients had less thick $\mathrm{CB}$ than in our study, ${ }^{14}$ therefore; bigger studies are still needed to compare the difference in iris and $\mathrm{CB}$ thickness between different ethnic groups before getting such conclusion.

Furthermore, our results showed no statistically significant difference between iris and CB thickness between tall and short patients, or between males and females. The population-based Kumejima study of Henzan et al on normal eyes in subjects 40 years and older mentions age as a factor, with the iris becoming thinner with advancing age. ${ }^{20}$ In our study, we noticed that patients younger than 40 year had a slight trend to have thicker iris, but that was not statistically significant. It is reasonable to assume that variation in iris thickness between patients is part of normal variation between different people.

Other than UBM that uses ultrasound waves, anterior segment OCT imaging can look at the structure of the iris producing high resolution cross-sectional images using different wavelengths of light (830-870nm and $1310 \mathrm{~nm}) .{ }^{20,21,24}$ When compared to anterior segment OCT, UBM has the advantage of enabling visualization of structures posterior to the iris such as the $\mathrm{CB}$, zonules and the peripheral lens, but UBM is more uncomfortable and requires a highly skilled operator in order to obtain good quality images. However, both UBM and anterior segment OCT gives quantitative measurements in a real time imaging. ${ }^{1,3,13,20,21}$ The anterior segment OCT was used to measure the normal iris thicknesses at 2 points (750 and $2000 \mu \mathrm{m}$ from the scleral spur and showed that the thickness of the iris was $0.406 \pm 0.075$ and $0.514 \pm$ $0.075 \mathrm{~mm}$ (mean \pm standard deviation [SD], respectively. ${ }^{22}$ In this study, we decided to use UBM rather than anterior segment OCT because UBM has better penetration and can give enough details about the depth of the CB. UBM also uses ultrasound waves that can penetrate the thick sclera that covers the limbus and the $\mathrm{CB}$. While anterior segment OCT uses infrared light waves that poorly penetrates through thick sclera and pigmented tissues. ${ }^{23}$

Herein, we tried to measure the normal thickness of the $\mathrm{CB}$ and the iris in normal eyes from homogenous population in the Middle East using ultrasound biomicroscopy. We obtained our results strictly following the same procedure that we (and others) use when imaging and measuring tumors of the iris and CB at King Hussein Cancer Center (KHCC), and thus our values on normal eyes are most reproducible in a clinical setting, and variations in iris and CB thickness can be considered as part of normal variation between different people. Even though, multiple factors may affect the iris and CB dimension in different people, and these have yet to be determined in future studies. Although this is a unique work on homogenous group from the same ethnicity evaluating the normal thickness of the iris and the CB using UBM, it is retrospective, of limited size, and limited by the age, gender, height for 46 adults.

Because of this selection bias, we decided to simply describe our findings that could be used as reference values in the Middle East region. We believe our study will be essential for the ophthalmic community worldwide and in the Middle East region, even though, a larger and more comprehensive prospective study should be performed to identify different variables that may affect the measured thickness for the $\mathrm{CB}$ and the iris to be used as reference data for eyes with different diseases that affect iris and/or CB thickness.

In conclusion, Gender, age, side, and height had no impact on iris and/or CB thickness, even though, nasal and superior iris thickness were more than temporal and inferior iris thickness respectively, and superior $\mathrm{CB}+$ ciliary processes thickness was higher than the inferior thickness. Findings of this study are essential for the ophthalmic 
community worldwide and in the Middle East region and can be used as a normative thickness data for the iris and $\mathrm{CB}$ in healthy eyes.

\section{Acknowledgments}

The authors thank all the patients for their participation in this study. Authors are thankful to the Foundation to Support the Development of Ophthalmology, Lublin, Poland, for the technical support during the publication of the results. The Foundation had no role in the design of the study; in the collection, analyses, or interpretation of data; in the writing of the manuscript, or in the decision to publish the results.

\section{Author Contributions}

All authors contributed to data analysis, drafting or revising the article, have agreed on the journal to which the article will be submitted, gave final approval of the version to be published, and agree to be accountable for all aspects of the work.

\section{Funding}

This research was supported in part by King Hussein Cancer Center, Amman, Jordan.

\section{Disclosure}

Professor Sandrine Zweifel reports grants, personal fees from Bayer Healthcare Pharmaceuticals, Novartis Pharma AG, Roche outside the submitted work. The authors report no other conflicts of interest in this work.

\section{References}

1. Pavlin CJ, Sherar MD, Foster FS. Subsurface ultrasound microscopic imaging of the intact eye. Ophthalmology. 1990;97:244-250. doi:10.1016/s0161-6420(90)32598-8

2. Marigo FA, Finger PT, McCormick SA, et al.; Anterior segment implantation cysts. Ultrasound biomicroscopy with histopathologic correlation. Arch Ophthalmol. 1998;116:1569-1575. doi:10.1001/ archopht.116.12.1569

3. Marigo FA, Esaki K, Finger PT, et al. Differential diagnosis of anterior segment cysts by ultrasound biomicroscopy. Ophthalmology. 1999;106:2131-2135. doi:10.1016/S0161-6420(99)90495-5

4. Marigo FA, Finger PT, McCormick SA, et al. Iris and ciliary body melanomas: ultrasound biomicroscopy with histopathologic correlation. Arch Ophthalmol. 2000;118:1515-1521. doi:10.1001/ archopht.118.11.1515

5. Finger PT, Reddy S, Chin K. High-frequency ultrasound characteristics of 24 iris and iridociliary melanomas: before and after plaque brachytherapy. Arch Ophthalmol. 2007;125:1051-1058. doi:10.1001/ archopht.125.8.1051

6. Yousef YA, ElRimawi AH, Nazzal RM, et al. Coat's disease: characteristics, management, outcome, and scleral external drainage with anterior chamber maintainer for stage $3 \mathrm{~b}$ disease. Medicine (Baltimore). 2020;99:(16)e19623. doi:10.1097/MD.0000000000019623
7. Finger PT, Meskin SW, Wisnicki HJ, Albekioni Z, Schneider S. High-frequency ultrasound of anterior segment retinoblastoma. $\mathrm{Am}$ J Ophthalmol. 2004;137:944-946. doi:10.1016/j.ajo.2003.10.042

8. Wada S, Kohno T, Yanagihara N, et al. Ultrasound biomicroscopic study of ciliary body changes in the post-treatment phase of Vogt-Koyanagi-Harada disease. $\mathrm{Br} \quad \mathrm{J}$ Ophthalmol. 2002;86:1374-1379. doi:10.1136/bjo.86.12.1374

9. Finger PT, Narayana K, Iacob CE, Samson CM, Latkany P. Giant sarcoid tumor of the iris and ciliary body. Ocul Immunol Inflamm. 2007;15:121-125. doi:10.1080/09273940601174053

10. Finger PT, Tran HV, Turbin RE, et al. High-frequency ultrasonographic evaluation of conjunctival intraepithelial neoplasia and squamous cell carcinoma. Arch Ophthalmol. 2003;121:168-172. doi:10.1001/archopht.121.2.168

11. Garcia JP, de la Cruz J, Rosen RB, Buxton DF. Imaging implanted keratoprostheses with anterior-segment optical coherence tomography and ultrasound biomicroscopy. Cornea. 2008;27:180-188. doi:10.1097/ICO.0b013e318159bc7d

12. Pavlin CJ, Harasiewicz K, Foster FS. Ultrasound biomicroscopy of anterior segment structures in normal and glaucomatous eyes. $\mathrm{Am}$ J Ophthalmol. 1992;113:381-389. doi:10.1016/s0002-9394(14)76159-8

13. Garcia JP, Spielberg L, Finger PT. High-frequency ultrasound measurements of the normal ciliary body and iris. Ophthalmic Surg Lasers Imaging. 2011;42:321-327. doi:10.3928/15428877-20110603-03

14. Gohdo T, Tsumura T, Iijima H, Kashiwagi K, Tsukahara S. Ultrasound biomicroscopic study of ciliary body thickness in eyes with narrow angles. Am $J$ Ophthalmol. 2000;129:342-346. doi:10.1016/s0002-9394(99)00353-0

15. Fiedorowicz M, Wełniak-Kamińska M, Świątkiewicz M, Orzeł J, Chorągiewicz T, Toro MD, Rejdak R, Bogorodzki P, Grieb P. Changes of Ocular Dimensions as a Marker of Disease Progression in a Murine Model of Pigmentary Glaucoma. Front Pharmacol. 2020 Sep 4;11:573238. doi:10.3389/fphar.2020.573238.

16. Chorągiewicz T, Nowomiejska K, Haszcz D, Nowakowska D, Avitabile T, Reibaldi M, Jünemann AGM, Toro MD, Rejdak R. Transscleral Fixation of Black Diaphragm Intraocular Lens in Complete Aniridia and Aphakia Due to Posttraumatic Eye Rupture: A Pilot Study. J Clin Med. 2019 Jan 5;8(1):46. doi:10.3390/jcm8010046.

17. Posarelli C, Toro MD, Rejdak R, et al. Safety and Efficacy of Second Ahmed Valve Implant in Refractory Glaucoma. J Clin Med. 2020;9: (7)2039. doi:10.3390/jcm9072039

18. Aptel F, Denis P. Optical coherence tomography quantitative analysis of iris volume changes after pharmacologic mydriasis. Ophthalmology. 2010;117:3-10. doi:10.1016/j.ophtha.2009.10.030

19. Invernizzi A, Cigada M, Savoldi L, Cavuto S, Fontana L, Cimino L. In vivo analysis of the iris thickness by spectral domain optical coherence tomography. $\mathrm{Br} J$ Ophthalmol. 2014;98:1245-1249. doi:10.1136/bjophthalmol-2013-304481

20. Henzan IM, Tomidokoro A, Uejo C, et al. Ultrasound biomicroscopic configurations of the anterior ocular segment in a population-based study the Kumejima Study. Ophthalmology. 2010;117:1720-1728, 1728.e1721. doi:10.1016/j.ophtha.2010.01.045

21. Izatt JA, Hee MR, Swanson EA, et al. Micrometer-scale resolution imaging of the anterior eye in vivo with optical coherence tomography. Arch Ophthalmol. 1994;112:1584-1589. doi:10.1001/ archopht.1994.01090240090031

22. Radhakrishnan S, Rollins AM, Roth JE, et al. Real-time optical coherence tomography of the anterior segment at $1310 \mathrm{~nm}$. Arch Ophthalmol. 2001;119:1179-1185. doi:10.1001/archopht.119.8.1179

23. He M, Wang D, Console JW, Zhang J, Zheng Y, Huang W. Distribution and heritability of iris thickness and pupil size in Chinese: the Guangzhou Twin Eye Study. Invest Ophthalmol Vis Sci. 2009;50:1593-1597. doi:10.1167/iovs.08-2735

24. Garcia JP, Rosen RB. Anterior segment imaging: optical coherence tomography versus ultrasound biomicroscopy. Ophthalmic Surg Lasers Imaging. 2008;39:476-484. doi:10.3928/15428877-20081101-02 
25. El Shakankiri NM, Bayoumi NH, Abdallah AH, El Sahn MM. Role of ultrasound and biomicroscopy in evaluation of anterior segment anatomy in congenital and developmental cataract cases. J Cataract Refract Surg. 2009;35(11):1893-1905. PMID: 19878821. doi:10.1016/j.jcrs.2009.07.007

26. Yousef YA, Al Jboor M, Mohammad M, et al. Safety and Efficacy of Intravitreal Chemotherapy (Melphalan) to Treat Vitreous Seeds in Retinoblastoma. Front Pharmacol. 2021;12:696787. doi:10.3389/ fphar.2021.696787
27. Ragab IT, Abdelkader AME, Kishk HM, Elshal AA. Assessment of post-operative pseudophakic glaucoma by ultrasound biomicroscopy. Clin Ophthalmol. 2020;14:1495-1501. PMID: 32581506; PMCID: PMC7276325. doi:10.2147/OPTH.S255626

28. Dada T, Aggarwal A, Vanathi M, et al. Ultrasound biomicroscopy in opaque grafts with post-penetrating keratoplasty glaucoma. Cornea. 2008;27(4):402-405. PMID: 18434841. doi:10.1097/ICO.0b013e31 $816373 \mathrm{c} 5$

\section{Publish your work in this journal}

Clinical Ophthalmology is an international, peer-reviewed journal covering all subspecialties within ophthalmology. Key topics include: Optometry; Visual science; Pharmacology and drug therapy in eye diseases; Basic Sciences; Primary and Secondary eye care; Patient Safety and Quality of Care Improvements. This journal is indexed on PubMed

Submit your manuscript here: https://www.dovepress.com/clinical-ophthalmology-journal
Central and CAS, and is the official journal of The Society of Clinical Ophthalmology (SCO). The manuscript management system is completely online and includes a very quick and fair peer-review system, which is all easy to use. Visit http://www.dovepress.com/ testimonials.php to read real quotes from published authors. 